\title{
Phosphorus decrease and climate variability: mediators of synchrony in phytoplankton changes among European peri-alpine lakes
}

\author{
ORLANE ANNEVILLE, ${ }^{*}{ }^{+}$SONJA GAMMETER ${ }^{\ddagger}$ AND DIETMAR STRAILE ${ }^{+}$ \\ ${ }^{*} I N R A$, Station d'hydrobiologie lacustre, Thonon les Bains, Cedex, France \\ ${ }^{\dagger}$ Limnologisches Institut, Universität Konstanz, Konstanz, Germany \\ ${ }^{\ddagger}$ Zurich Water Supply, Postfach, Zürich, Switzerland
}

\begin{abstract}
SUMMARY
1. In an attempt to discern long-term regional patterns in phytoplankton community composition we analysed data from five deep peri-alpine lake basins that have been included in long-term monitoring programmes since the beginning of the 1970s. Local management measures have led to synchronous declines in phosphorus concentrations by more than $50 \%$ in all four lakes. Their trophic state now ranges from mesotrophic to oligotrophic.

2. No coherence in phytoplankton biomass was observed among lakes, or any significant decrease in response to phosphorus (P)-reduction (oligotrophication), except in Lakes Constance and Walen.

3. Multivariate analyses identified long-term changes in phytoplankton composition, which occurred coherently in all lakes despite the differing absolute phosphorus concentrations.

4. In all lakes, the phytoplankton species benefiting from oligotrophication included mixotrophic species and/or species indicative of oligo-mesotrophic conditions.

5. A major change in community composition occurred in all lakes at the end of the 1980s. During this period there was also a major shift in climatic conditions during winter and early spring, suggesting an impact of climatic factors.

6. Our results provide evidence that synchronous long-term changes in geographically separated phytoplankton communities may occur even when overall biomass changes are not synchronous.
\end{abstract}

Keywords: long-term changes, multivariate analyses, oligotrophication, phytoplankton community, temporal coherence

\section{Introduction}

Long-term limnological plankton studies usually focus on individual waterbodies and their catchment area and it has been shown often that changes in

Correspondence: Orlane Anneville, INRA, Station

d'hydrobiologie lacustre, 75 avenue de Corzent, BP 511,

F-74203 Thonon les Bains Cedex, France.

E-mail: orlane.anneville@thonon.inra.fr

Present address: Sonja Gammeter, PO Box 1279, Midland WA 6936, Australia. plankton dynamics vary significantly because of both extrinsic forces and intrinsic processes (Anneville et al., 2002b, 2004). These processes and local changes are often described in detail, but it is difficult to extrapolate (Kratz et al., 1998; Baines et al., 2000) and thus to predict how other lakes might react to humandriven environmental change or large-scale forcing such as global warming (Pace, 2001). As a result, recent limnological research has been oriented towards 'regional ecology' (Magnuson \& Kratz, 2000), an approach that compares lake dynamics and focuses on how similar sets of lakes behave over time. These 
analyses are an important means to understand longterm lake dynamics at the regional level.

Synchrony is defined as the correlation between concurrent time series of a variable measured in several lakes (Baines et al., 2000), and temporal coherence is referred to as the degree to which variables behave similarly over time (Rusak et al., 1999). Essentially, synchrony and coherence are thus used interchangeably, with coherence having a distinct quantitative connotation. Adjacent lakes often show strong coherence in physical or even chemical changes, whereas quantitative biological variables are usually less coherent (Kratz et al., 1998; Magnuson \& Kratz, 2000). The reduced coherence of biological variables reflects a number of factors: synchrony is affected by the directness of the mechanistic linkages to environmental forcing, the number of processes affecting variable dynamics, and the sensitivity of variable dynamics to locally unique conditions (Kratz et al., 1998). Analyses of coherence in biological variables usually focus on integrative quantitative parameters (e.g. chlorophyll $a$ concentration, species richness) or individual taxa abundance, while few investigations into coherence across lakes have been directed at community changes.

The species composition, especially of phytoplankton, however, is known to be a reliable indicator of changes in environmental conditions, most notably changes related to nutrient loading (Rosén, 1981; Reavie \& Smol, 2001). Furthermore, phytoplankton composition strongly influences food quality for higher trophic levels and thus plays an important role in energy transfer within food webs (Gaedke, Hochstädter \& Straile, 2002). Finally, phytoplankton population changes are often of key concern for lake management authorities when nuisance species disturb recreational activities or threaten the use of drinking water.

These points underline the importance and necessity of looking at comparative changes in phytoplankton composition. Here we examine whether lakes within a region exhibit synchronous patterns in phytoplankton biomass and community composition. The studied lakes are all deep peri-alpine lakes which went through a history of eutrophication and oligotrophication during the last century. As they are geographically close, similarities in climate forcing are also expected. Hence, these lakes make ideal candidates for a study of coherence in phytoplankton community response to changes in nutrient loading and climate variability.

\section{Methods}

\section{Lake data}

Lakes Geneva, Constance, Zurich and Walen are located within $200 \mathrm{~km}$ of each other. Lakes Geneva and Constance have similar dimensions (Table 1) and are larger and deeper than Lake Walen and Lake Zurich; the latter is separated into two basins by a natural sill (about $3 \mathrm{~m}$ deep). The lakes are all monomictic and freeze very rarely. However, mixing does not affect the entire water column every year.

Data series on physical, chemical and biological variables were available for all the lakes dating back to the 1970s (Table 1). Samples were taken as part of monitoring programmes by federal and regional authorities (the Commission Internationale pour la Protection des Eaux du Léman contre la pollution, CIPEL, for Lake Geneva; the Zurich Water Supply for Lakes Zurich and Walen; and the Limnological Institute, University of Constance, for Lake Constance). The sampling stations were all pelagic. In Lake Zurich, sampling was conducted at two stations, one in the lower basin and the other one in the upper basin. Physical and biological parameters were measured monthly in Lake Zurich and Walen. In Lake Geneva, sampling was performed once a month from 1974 to 1980 and then bi-monthly. In Lake Constance, sampling was conducted weekly during the growing season, except in 1981 when sampling took place every 2-3 days, and in 1987 when samples were taken on two consecutive days per week. No measurements are available for the second half of 1983.

In all lakes, temperatures and nutrient concentrations were measured at discrete depths between the surface and the bottom of the lake. Dissolved inorganic phosphorus (DIP) was determined using the acid molybdate method (AFNOR, 1982) in Lake

Table 1 Morphological attributes of the study lakes and years for which data on phytoplankton compositions are available

\begin{tabular}{lcccc}
\hline & $\begin{array}{l}\text { Lake } \\
\text { area } \\
\left(\mathrm{km}^{2}\right)\end{array}$ & $\begin{array}{l}\text { Max } \\
\text { depth } \\
(\mathrm{m})\end{array}$ & $\begin{array}{l}\text { Mean } \\
\text { depth } \\
(\mathrm{m})\end{array}$ & $\begin{array}{l}\text { Period } \\
\text { covered }\end{array}$ \\
\hline Lake & 582 & 309 & 153 & $1974-2000$ \\
Lake Geneva & 539 & 253 & 101 & $1979-1998$ \\
Lower Constance & 65 & 136 & 51 & $1972-2000$ \\
Upper Lake Zurich & 20 & 48 & 23 & $1972-2000$ \\
Lake Walen & 24 & 145 & 103 & $1972-2000$ \\
\hline
\end{tabular}


Geneva and with an automated molybdenum-blue method with ascorbic acid (DIN EN 1189; DEV (1996)) in Lakes Constance, Zurich and Walen. Total phosphorus (TP) concentrations were measured with the same method after unfiltered samples were digested with potassium-peroxodisulphate.

In Lakes Zurich and Walen, phytoplankton samples were taken at nine discrete depths between surface and $20 \mathrm{~m}$. In Lake Constance, the water column from 0 to $20 \mathrm{~m}$ depth was sampled 10 times with a 2-m long tube, and two to four integrated samples were counted. In the present study, average values of the uppermost $20 \mathrm{~m}$ are used, with the exception of Lake Geneva, where water samples for estimating phytoplankton species and biomass were collected in the upper $10 \mathrm{~m}$ using an integrating sampler (Pelletier, INRA patent 1978). In all the lakes, phytoplankton identification and cell counts were carried out in sedimentation chambers under an inverted microscope (Utermöhl, 1958). Species biovolumes were derived from cell numbers and mean cell volumes using geometrical models. Total biomass was then estimated by adding the biovolumes for each species, assuming a fresh weight of $1 \mathrm{~g} \mathrm{~cm}^{-3}$. The personnel responsible for identifying the species have changed during the studied period, except in Lake Geneva. In consequence, in order to minimise the error of species identification and maximise interannual and interlake comparability, data analyses were conducted at the generic level.

\section{Detection of long-term changes}

Analysis of structural changes in communities requires comparable long-term datasets and the use of methods permitting simultaneous consideration of all species. The detection and description of phytoplankton long-term changes were obtained by applying a derivative of Principal Component Analysis (PCA). As changes in species composition occur at different temporal scales and our aim was to focus on interannual variability, we used a method referred to as between-groups analysis (ADE4 software package, http:/ / pbil.univ-lyon1.fr/ADE-4/ADE-4.html; Thioulouse et al., 1997). This is a multivariate method previously used to analyse interannual changes in the phytoplankton species composition in Lake Geneva (Anneville, Ginot \& Angeli, 2002a). The method is adapted to analyse matrices where the objects are gathered by group (Dolédec \& Chessel, 1989) and its goal is to focus on between-group variability. The method consists of a PCA run on the group-weighted average values of the variables. The weight of a group is computed during the analysis and equals the number of samples pertaining to this group.

We had 10 matrices of phytoplankton biomass corresponding to the five studied lakes for two seasons (spring and autumn). A between-groups analysis was computed for each season and each lake separately. Each data matrix included biomasses of phytoplankton genera as variables and samples collected from March to May (for spring) or July to September (for summer) as objects. In each matrix the samples were grouped by year so that the focus on between-groups differences was equivalent to the focus on interannual variability. Only genera present in more than $5 \%$ of the samples were included in the analyses. Biomass of the phytoplankton genera was $\ln (x+1)$ transformed and centred by genera before averaging; as a result, uncommon taxa (i.e. those absent in many samples) had little variance and therefore little weight in the analysis. The statistical significance of the dispersion of the centres of gravity was systematically tested with permutation tests. The results of a between-groups analysis can be interpreted like a PCA, i.e. the relative position of the objects to each other in a plane reflects their similarity. To ensure objective interpretation of the distribution of years within the planes, homogeneous groups of years were identified using cluster analyses (with Euclidean distances and an average link clustering strategy) on the coordinates of the gravity centre of the years. All the analyses have been undertaken with the ADE4 package.

\section{Measure of coherence and determinant of synchrony}

The degree to which variables behaved similarly over time (i.e. their 'temporal coherence') was analysed by determining the correlation coefficients between specific lake pairs across all variables. Variables tested for synchrony were phosphorus concentration, phytoplankton biomass and phytoplankton composition expressed as the scores of the principal component axis. We considered the time series of two lakes coherent if correlation coefficients were significantly different from zero after Bonferroni correction. Pearson product-moment correlations were used when variables were normally distributed; otherwise 
Spearman rank correlations were computed. Normality of distribution was assessed using the KolmogorovSmirnov test. The relationships between phytoplankton community composition (principal component scores) and trophic state (TP concentrations) and climate (winter-spring average water temperature) were additionally assessed by multiple regressions of linearly detrended variables and mixed models of untransformed variables. In the mixed models we accounted for autocorrelation by considering autocorrelated errors (Littell et al., 1996). As TP concentrations declined exponentially in the lakes, TP was transformed logarithmically before regressions and mixed model analyses. Multiple regression and mixed models were performed with SAS (SAS Institute 1999).

\section{Results}

Long-term changes in phosphorus concentration and water-temperature

Phosphorus concentrations decreased synchronously in all lakes, with all the lake pair correlations being highly significant. In Lakes Geneva and Constance, the decrease started at the beginning of the 1980s, whereas in the other lakes, it began as early as in the 1970s (Fig. 1). However, actual TP concentrations measured during winter mixis differed among lakes. Lake Geneva, Lake Constance and the Lower Lake Zurich had similar concentrations, with TP concentrations declining from 80 to $100 \mu \mathrm{g} \mathrm{P} \mathrm{L}^{-1}$ to around $25 \mu \mathrm{g} \mathrm{P} \mathrm{L}{ }^{-1}$ in Lake Geneva and Lower Lake Zurich (69-75\% reduction), and to $13 \mu \mathrm{g} \mathrm{P} \mathrm{L} \mathrm{P}^{-1}$ in Lake Constance (85\% reduction). In contrast, Upper Lake Zurich and Lake Walen had much lower initial concentrations, decreasing from 43 to $14 \mu \mathrm{g} \mathrm{P} \mathrm{L}^{-1}$ (67\% reduction) and from 31 to $4 \mu \mathrm{g} \mathrm{P} \mathrm{L}{ }^{-1}$ (87\% reduction), respectively. Furthermore, in all the lakes, decreases in DIP concentrations were accompanied by an earlier appearance of a P-depleted surface layer (with $<10 \mu \mathrm{g} \mathrm{P} \mathrm{L}{ }^{-1}$ ) and an increase of the vertical extension of this P-depleted zone (Fig. 2). In the more eutrophic lakes (Lakes Geneva, Constance, and Lower Lake Zurich), concentrations $<10 \mu \mathrm{g} \mathrm{P} \mathrm{L}{ }^{-1}$ were not observed during winter and spring, but occurred during summer, reaching depths of $20 \mathrm{~m}$. At the end of the 1980s, a shift occurred in the timing of surface P-depletion and the depleted layer extended below 20-30 $\mathrm{m}$ in summer. Since 1987 in Lake Constance and 1989 in Lakes Geneva and Lower Lake Zurich, the P-depleted zone has appeared as early as April. The surface P-depletion has persisted throughout the year since 1987 in Upper Lake Zurich and 1985 in Lake Walen. Furthermore, the DIP concentration in Upper

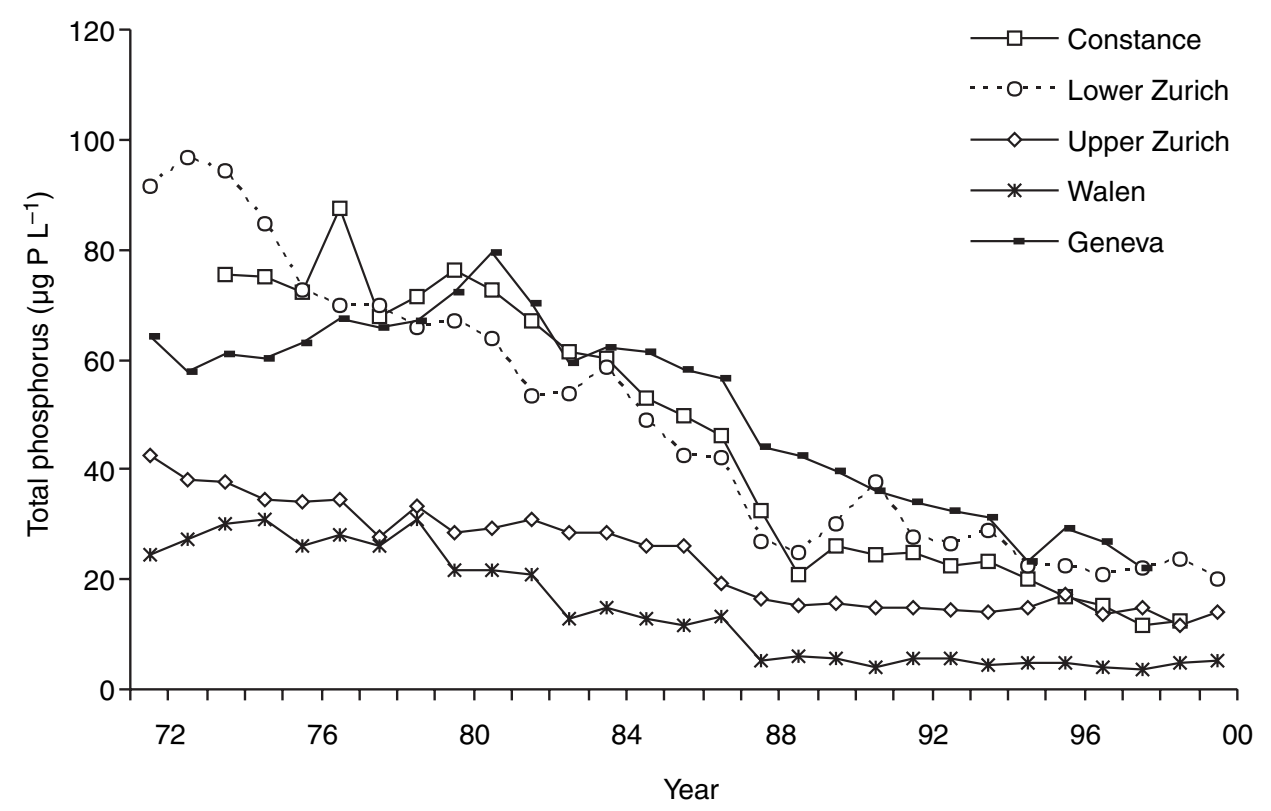

Fig. 1 Long-term changes in winter total phosphorus concentrations in Lakes Geneva and Constance, both basins of Lake Zurich, and Lake Walen. 


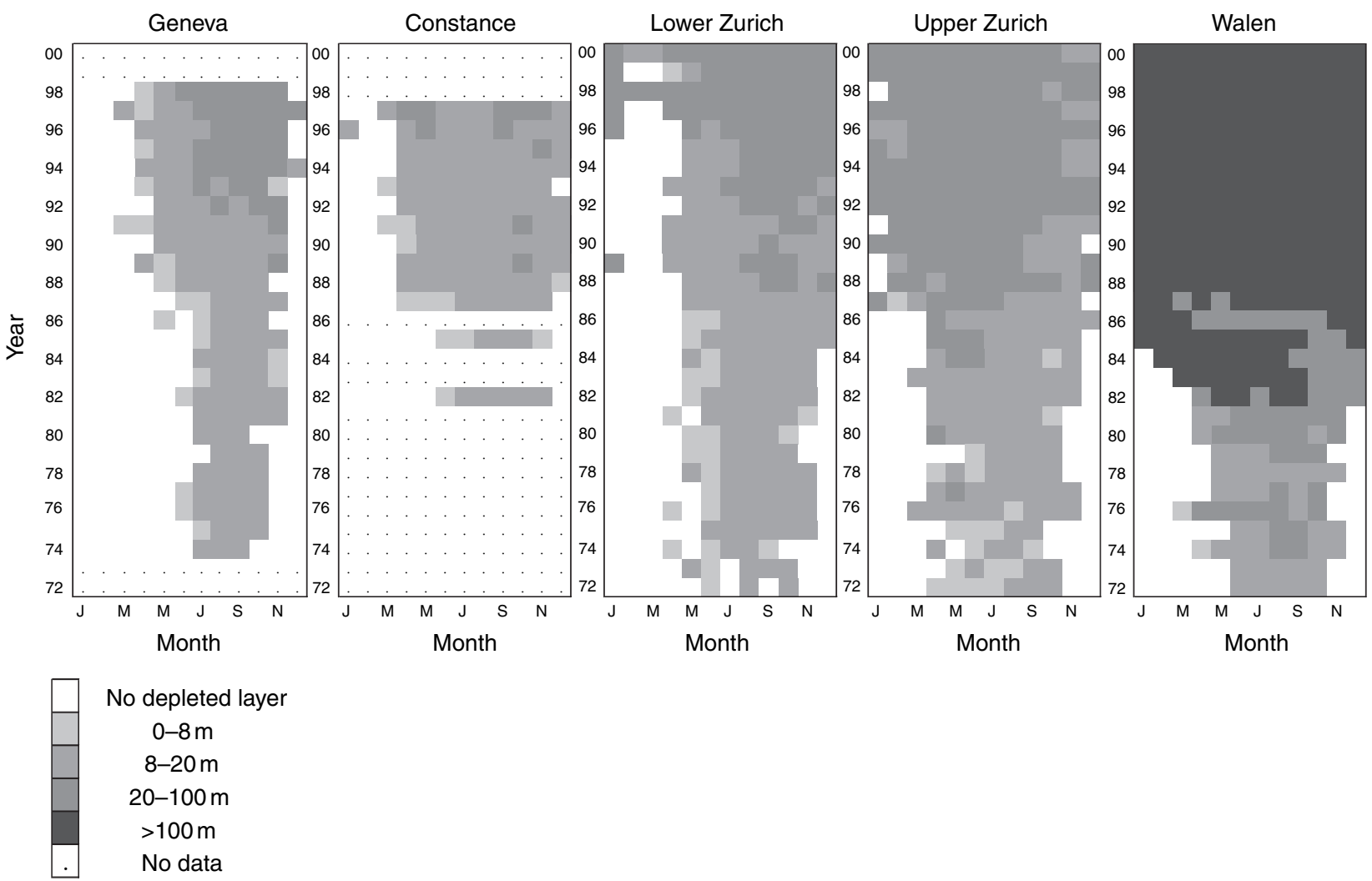

Fig. 2 Temporal maps describing the seasonal (abscissa) and interannual (ordinates) changes in the depth of the phosphorus depleted layer, which is defined as the depth to which dissolved inorganic phosphorus concentrations (DIP) are $<10 \mu \mathrm{g} \mathrm{P} \mathrm{L}{ }^{-1}$. In Lake Constance only averages by strata $(0-8,8-20$ and $20-100 \mathrm{~m})$ were available. In this lake, a depth corresponding to the interval 20-100 $\mathrm{m}$ indicates that the average DIP concentration within this stratum was $<10 \mu \mathrm{g} \mathrm{P} \mathrm{L}{ }^{-1}$.

Lake Zurich and Lake Walen has been low throughout the entire water column since the mid-1980s.

Winter-spring (December of the previous year to June) average water temperatures measured over the first $10 \mathrm{~m}$ underwent similar long-term changes (Fig. 3). Two distinct but sequential periods could be identified in each lake: a cold one from 1976 to 1987 and a warm one from 1988 to 2000.

\section{Long-term changes in phytoplankton}

Both spring and summer phytoplankton biomass showed strong interannual variability (Fig. 4). In the two lakes with the lowest TP concentrations (Upper Lake Zurich and Lake Walen), spring biomass dropped at the beginning of the 1990s and remained low. In the other lakes, spring biomass did not show such a decrease. In Lake Walen, phytoplankton biomass also decreased during summer. In Lake Constance the summer biomass decreased between
1978 and 1987 and afterwards remained around $1000 \mu \mathrm{g}$ fresh mass $\mathrm{L}^{-1}$.

Changes in phytoplankton composition are presented in Figs 5 \& 6 . The first planes of the betweengroups analyses explained $37-54 \%$ of the total inertia in spring and $43-57 \%$ in summer. Thus, two dimensions accounted for almost half of the year-to-year variation in the phytoplankton community composition at the genus level. The projection of samples and the gravity centre of the years within the first plane reveal local patterns that differ from one season to another.

The spring period differed among lakes in some years (e.g. 1995 in Lake Geneva; 1976 in Upper Lake Zurich), while other years were gathered in two or three main clusters, exhibiting periods of relative interannual similarity (Fig. 5). In summer, clear temporal trajectories appeared within the first plane in all lakes. In each lake, the series fell into two main clusters (Fig. 6), marking two periods with significantly 


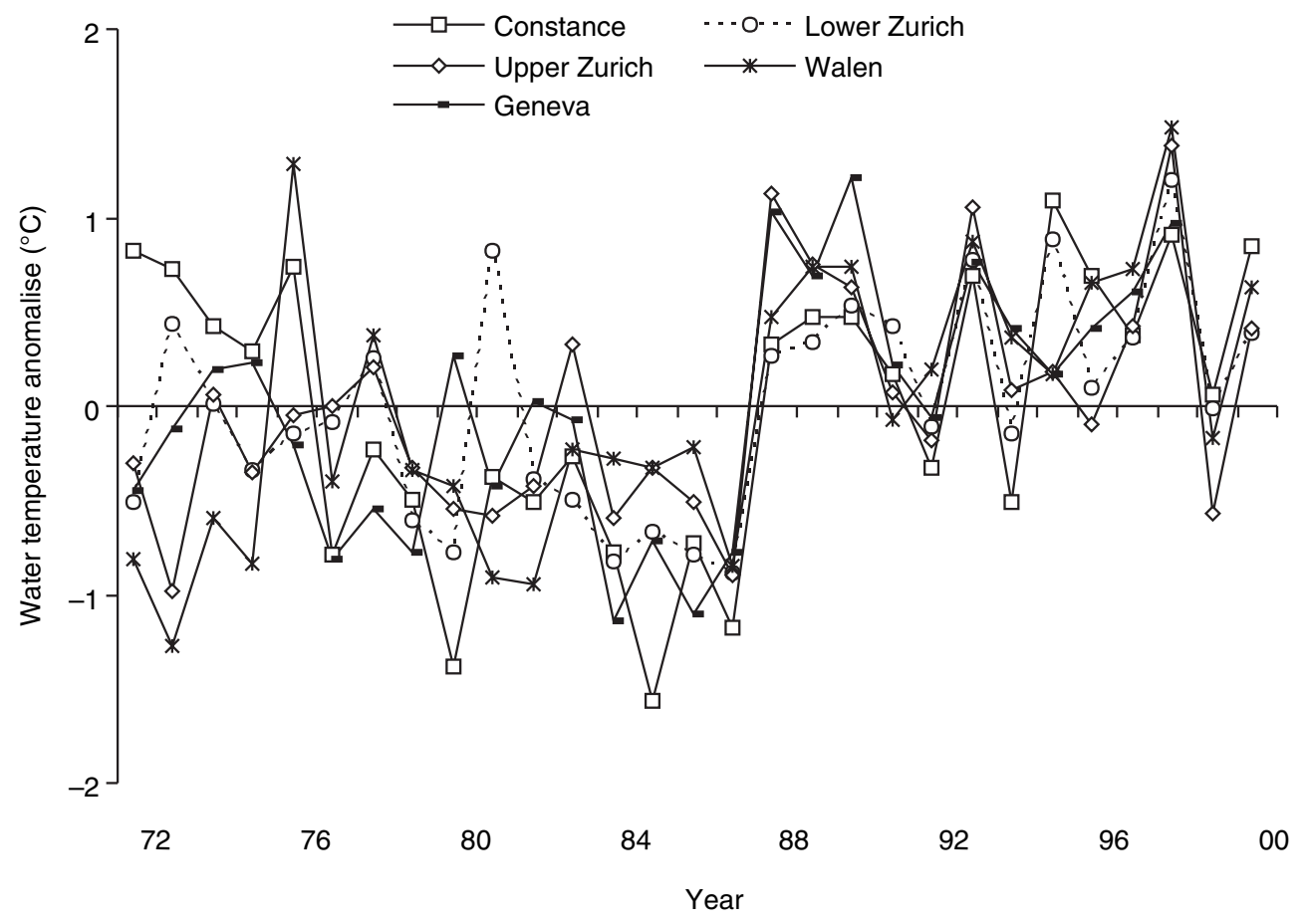

Fig. 3 Long-term changes in winter-spring (December of the previous year to June) water temperature anomalies measured in the first $10 \mathrm{~m}$ of Lakes Geneva and Constance, Lower and Upper Lake Zurich, and Lake Walen from 1974 to 2000.

different phytoplankton composition (between-group permutation test, $P<0.001)$. The first one lasted from the 1970 s to 1987 , and the second one from 1988 to 2000. This division is mostly because of the long-term trend shown on the first axis (Fig. 7), which accounts for more than one-third of the inertia in almost all the lakes.

\section{Temporal coherence in phytoplankton}

A significant correlation between the time series of spring phytoplankton biomass was found only between Lake Walen and Upper Lake Zurich $(P<0.01)$. Summer biomass showed no coherent development during the study years. Spring phytoplankton community changes described by axis II showed only poor synchrony among lakes. This observation is also true for summer values. In contrast, the main changes described by axis I were coherent between most of the pairs of lakes for both spring and summer. In spring, the years were distributed almost chronologically on axis I for Lakes Geneva and Constance and both basins of Lake Zurich. These changes in phytoplankton composition represent significant temporal coherence for seven of ten possible pairwise comparisons.
In summer, a significant temporal coherence was observed for all pairwise comparisons. For this season, the ordination of the year reflects a shift that occurred simultaneously in the late 1980s (Fig. 7).

\section{Coherence factors}

The considered variables differed in overall synchrony. Phosphorus concentration and summer phytoplankton communities expressed as the first principal component were the most synchronous variables for all lake pairs and displayed significant coherence. The other variables only exhibited synchrony among a few lakes. Phytoplankton biomass was correlated significantly with TP concentrations in Lake Walen, both in spring and summer $(P<0.05)$. In Lake Constance, a significant relationship between phytoplankton biomass and TP emerged only during summer ( $r=0.49$, $P<0.05)$. In the other lakes, spring and summer biomass displayed no significant positive correlations with TP concentration.

As only summer changes described by axis I displayed synchrony between all pairs of lakes, focus is placed on this axis. In summer, changes in phytoplankton composition (as described by the scores of 

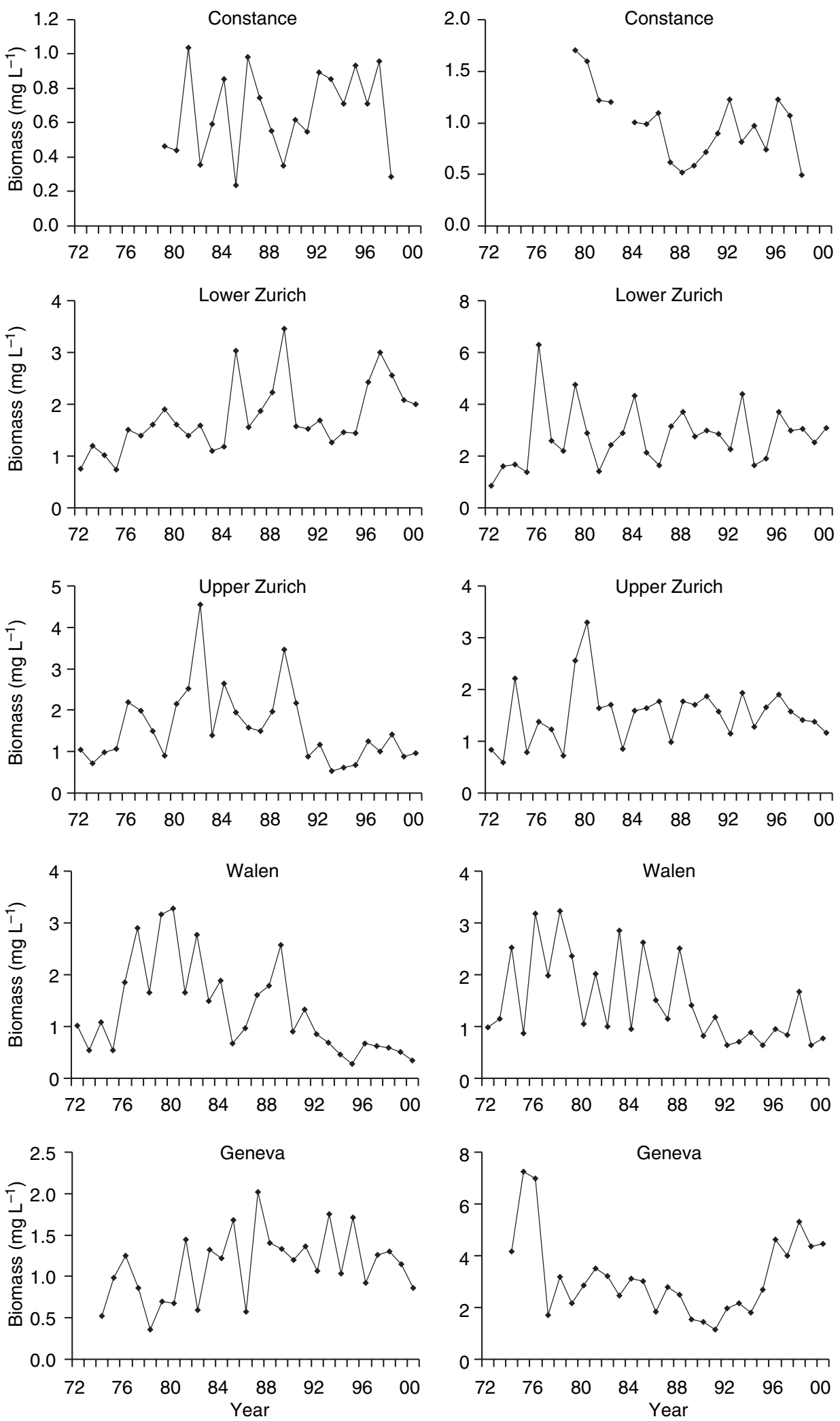

Fig. 4 Interannual fluctuations in phytoplankton biomass (expressed as fresh mass $\mathrm{L}^{-1}$ ) in Lakes Geneva and Constance, Lower and Upper Lake Zurich, and Lake Walen. 

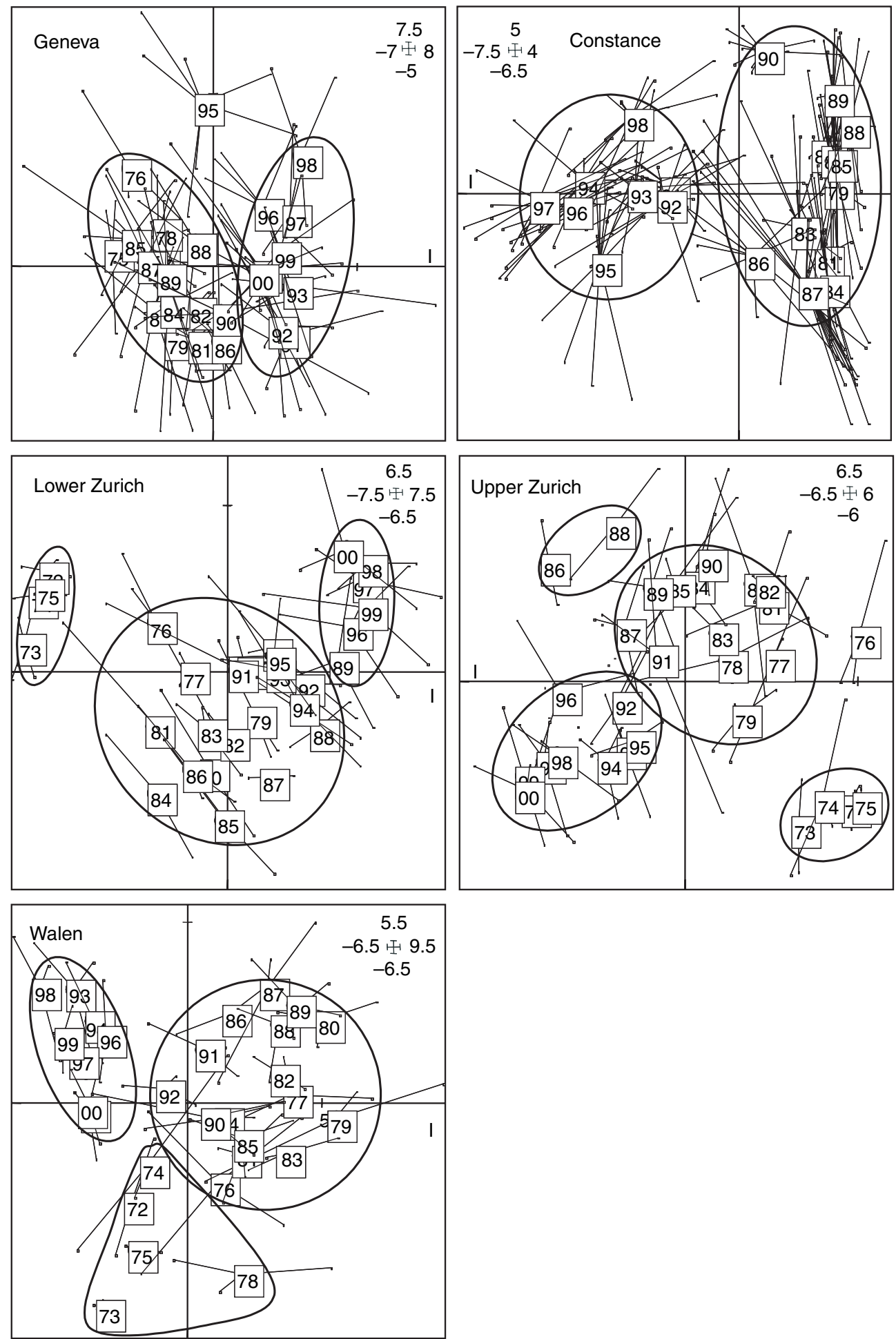

Fig. 5 Distribution of the spring samples within the first plane (defined by axes I and II) from the between-group PCA run separately on data from Lake Geneva, Lake Constance, both basins of Lake Zurich, and Lake Walen. Standard samples scores (dots) are linked to the centre of gravity (large squares) of the corresponding year. The groupings of years indicated by ellipses were identified by cluster analysis. 

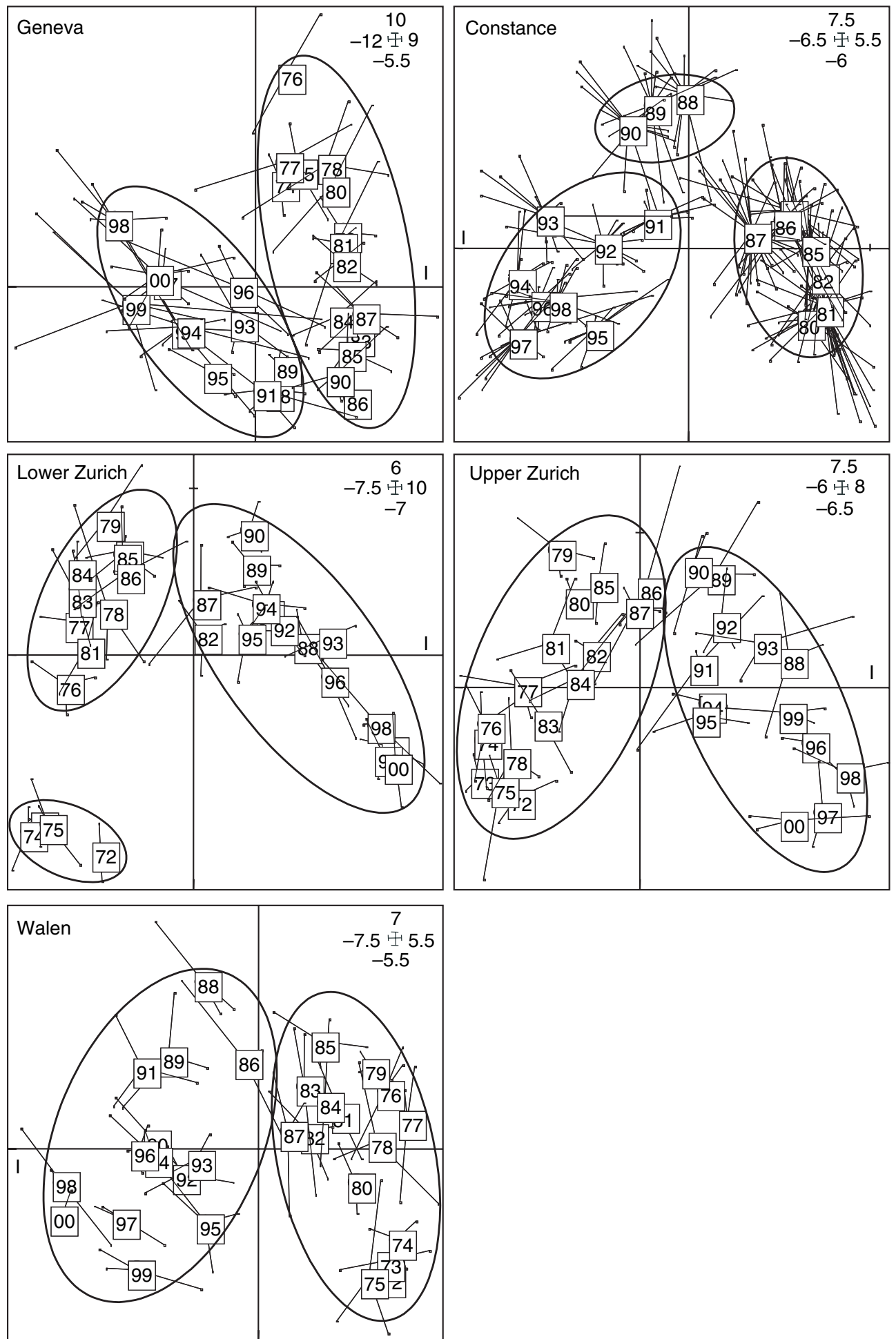

Fig. 6 Distribution of the summer samples within the first plane (defined by axes I and II) from the between-group PCA run separately on data from Lakes Geneva and Constance, both basins of Lake Zurich, and Lake Walen. Standard samples scores (dots) and their centres of gravity (large squares) are indicated for each group of years. The groupings of years indicated by ellipses were identified by cluster analysis. 


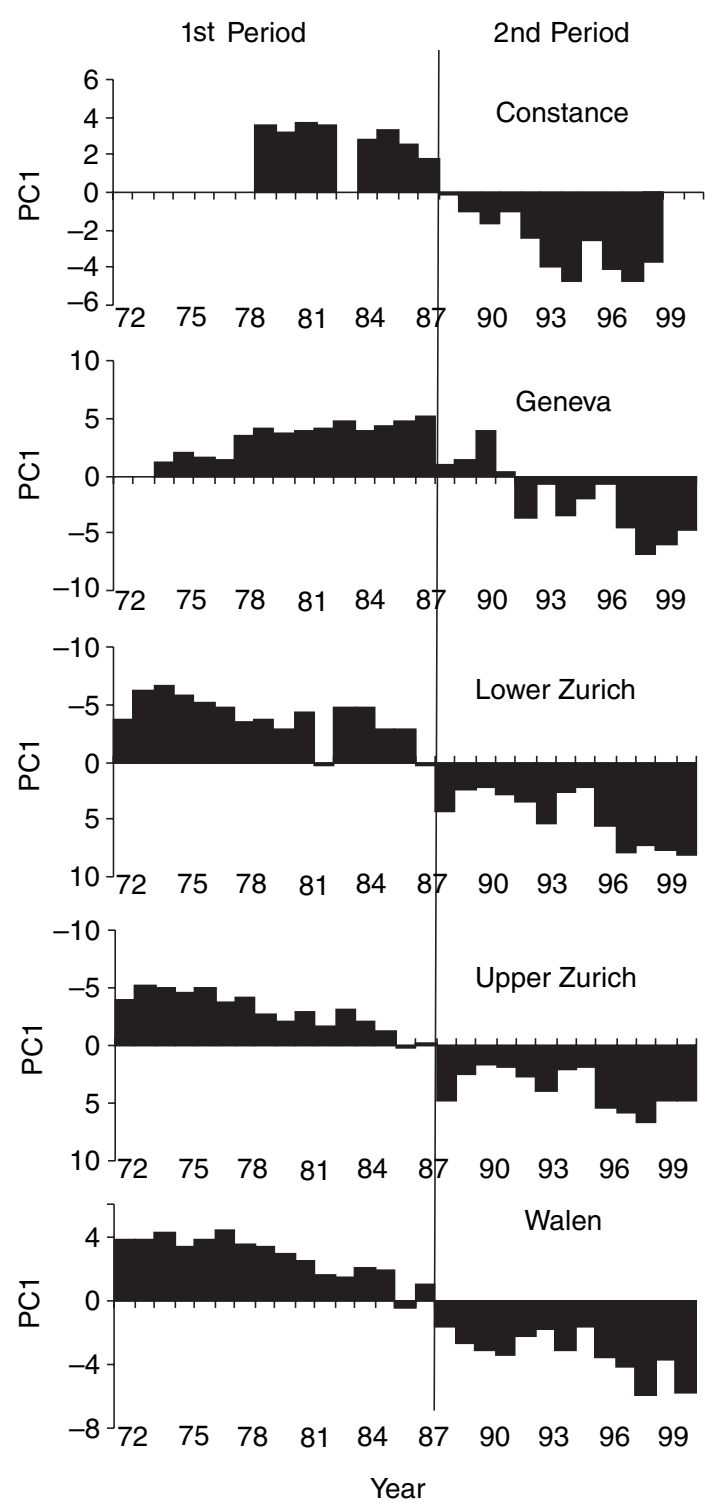

Fig. 7 Long-term changes of summer phytoplankton composition as revealed by the first principal component of a betweengroup PCA.

the first principal component, PC1) showed strong correlation with phosphorus concentration $(P<0.001)$ when the lakes were analysed separately. There were also strong correlations between summer phytoplankton changes and winter-spring water temperature $(P=0.001$ to 0.045$)$. However, as PC1 scores, TP concentrations and winter temperatures showed strong trends, these significant relations were to be expected. Collinearity in explanatory variables makes it difficult to determine the relative role of $\mathrm{TP}$ concentration versus winter temperature for phytoplankton community structure. When considering linearly detrended variables in multiple regression models, PC1 scores were significantly related to TP concentration in Lakes Geneva $(P<0.01)$ and Walen $(P<0.01)$ and Lower Lake Zurich $(P<0.05)$ whereas winter temperature was significantly related to PC1 scores in Upper Lake Zurich $(P<0.05)$. Neither winter temperature nor TP concentration was significantly related to the PC1 scores of the Lake Constance phytoplankton. Because of the high collinearity between the variables and time, detrending removed most of the variability, and there is therefore a high probability that independent variables were considered non-significant. When using mixed models with autocorrelated errors and the lakes as random variables, both TP as well as winter temperature appeared to influence PC1 scores (Table 2). The best model according to Akaike's information criterion consisted of winter temperature $(P<0.01)$, and TP concentration (ns) and their interaction $(P<0.01)$ as fixed effects. However, the problem of collinearity of variables with time in the mixed models was still present. Hence, it is necessary to interpret the longterm summer trends in phytoplankton composition and identify the genera contributing the most to the formation of axis I in each lake. The inertia of projections on the principal component can be decomposed into a sum of absolute contributions of the variables to the definition of the axis. Only the genera whose contributions were $>1 \%$ were retained (Table 3). The two time-periods identified by the between-groups analyses (before and after 1987;

Table 2 Solution for the fixed effects of mixed models with summer PC1 scores as dependent variable and combinations of independent variables total phosphorus concentration (TP) and temperature (T). TP was logarithmically transformed before analyses, $\mathrm{T}$ represents winter temperatures. Models are arranged in order of their Akaike information criterion (AIC), with smaller values indicating superior, i.e. more parsimonious models.

\begin{tabular}{|c|c|c|c|c|c|}
\hline Model & AIC & Variable & $\begin{array}{l}\text { Parameter } \\
\text { estimate }\end{array}$ & $t$-value & $P$-value \\
\hline \multirow[t]{3}{*}{1} & \multirow[t]{3}{*}{488} & $\mathrm{TP}$ & $-6.2 \pm 4.9$ & -1.27 & 0.2 \\
\hline & & $\mathrm{T}$ & $-2.4 \pm 0.8$ & -2.85 & 0.005 \\
\hline & & $\mathrm{TP} \times \mathrm{T}$ & $1.5 \pm 0.6$ & 2.70 & 0.008 \\
\hline 2 & 495 & $\mathrm{TP}$ & $6.7 \pm 1.5$ & 4.42 & 0.0001 \\
\hline \multirow[t]{2}{*}{3} & \multirow[t]{2}{*}{496} & $\mathrm{TP}$ & $6.4 \pm 1.5$ & 4.20 & 0.0001 \\
\hline & & $\mathrm{T}$ & $-0.2 \pm 0.2$ & -0.90 & 0.35 \\
\hline 4 & 512 & $\mathrm{~T}$ & $-0.3 \pm 0.2$ & -1.6 & 0.11 \\
\hline
\end{tabular}


Table 3 List of phytoplankton genera and their contribution (\%) to the formation of axis I for Lake Geneva (G), Lake Constance (C), Lower Lake Zurich (LZ), Upper Lake Zurich (UZ) and Lake Walen (W)

\begin{tabular}{|c|c|c|c|c|c|c|c|c|c|c|c|c|c|}
\hline \multirow[b]{2}{*}{ Associations } & \multirow[b]{2}{*}{ Habitat } & \multirow[b]{2}{*}{ Tolerances } & \multirow[b]{2}{*}{ Genus } & \multicolumn{5}{|c|}{$\begin{array}{l}\text { First period } \\
(1972-1987)\end{array}$} & \multicolumn{5}{|c|}{$\begin{array}{l}\text { Second period } \\
(1988-2000)\end{array}$} \\
\hline & & & & G & $\mathrm{C}$ & $\mathrm{LZ}$ & $\mathrm{UZ}$ & W & G & $\mathrm{C}$ & $\mathrm{LZ}$ & UZ & $\mathrm{W}$ \\
\hline Lo & Mesotrophic & Segregated nutrients & Peridinium & 2 & & & & & & & & & \\
\hline $\mathrm{N}$ & Mesotrophic & Nutrient deficiency & Cosmarium & 1 & & & & & & & & & \\
\hline \multirow[t]{2}{*}{ K } & Nutrient-rich & & Aphanothece & 3 & & & & & & & & & \\
\hline & Eutrophic & & Phacotus & 2 & & & & & & & & & \\
\hline B & Mesotrophic & Light deficiency & Aulacoseira & & 3 & & & & & & & & \\
\hline $\mathrm{H}$ & Eutrophic & Low nitrogen & Anabaena & & & 1 & & & & & & & \\
\hline $\mathrm{D}$ & Enriched, turbid & & Nitzschia & & & & & 7 & & & & & \\
\hline $\mathrm{D}$ & Enriched, turbid & & Diatoma & & & & & 1 & 18 & 6 & & & \\
\hline Y & Enriched & Low light & Cryptomonas & & & & & 6 & & & & & \\
\hline $\mathrm{Lm}$ & Eutrophic & Very low $\mathrm{C}$ & Ceratium & 1 & & & & 1 & & 4 & & & \\
\hline $\mathrm{Lm} / \mathrm{M}$ & Eutrophic/eutrophic & Very low C/high insolation & Microcystis & & & & & & & 1 & & & \\
\hline $\mathrm{F}$ & Clear epilimnia & Low nutrients, high turbidity & Sphaerocystis & 1 & & & & & & & & & \\
\hline $\mathrm{F}$ & Clear epilimnia & Low nutrients, high turbidity & Dictyosphaerium & 1 & & & & & & & & & \\
\hline $\mathrm{F}$ & Clear epilimnia & Low nutrients, high turbidity & Oocystis & 1 & & 5 & & & & & & & \\
\hline $\mathrm{J}$ & Enriched & & Pediastrum & 2 & & 1 & & & & & & & \\
\hline $\mathrm{T}$ & Well-mixed epilimnia & Light deficiency & Mougeotia & & 10 & 2 & & & 5 & & & & \\
\hline $\mathrm{T}$ & Well-mixed epilimnia & Light deficiency & Tribonema & & & & & & 1 & & & & \\
\hline $\mathrm{C}$ & Mixed, eutrophic & Light and $\mathrm{C}$ deficiencies & Stephanodiscus & 2 & 6 & & & & & & & 1 & \\
\hline C & Mixed, eutrophic & Light and $\mathrm{C}$ deficiencies & Asterionella & 1 & 2 & & & & & & & & \\
\hline $\mathrm{P}$ & Eutrophic, epilimnia & Mid light and C deficiency & Fragilaria & 4 & & & & 4 & & & & & \\
\hline \multirow[t]{2}{*}{$\mathrm{P}$} & Eutrophic, epilimnia & Mid light and C deficiency & Staurastrum & 3 & & 5 & & 2 & & & & & \\
\hline & & & Ulothrix & & 1 & 4 & 4 & & & & & & \\
\hline G & Nutrient-rich & High light & Eudorina & 8 & & 2 & 2 & 1 & & & & & \\
\hline \multirow[t]{2}{*}{ G } & Nutrient-rich & High light & Pandorina & & 2 & & & 1 & & & & & \\
\hline & & & Tetraedron & & & & & & 2 & & & & \\
\hline S1 & Turbid mixed layers & Highly light deficient & Pseudanabaena & & & & & & 2 & & & & \\
\hline $\mathrm{R}$ & Mesotrophic & Low light, strong segregation & Oscillatoria & & & & & & 3 & & & & \\
\hline \multirow[t]{6}{*}{$\mathrm{R}$} & Mesotrophic & Low light, strong segregation & Planktothrix & & & & & & & & 18 & & \\
\hline & & & Pseudopedinella & & & & & & & 3 & & & \\
\hline & Oligo-mesotrophic & & Chrysochromulina & & & & & & & 4 & & & \\
\hline & & & Chrysolykos & & & & & & & & & & 2 \\
\hline & Oligo-mesotrophic & & Gymnodinium & & & & & & & 16 & & & \\
\hline & & & Achnanthes & & & & & & & 1 & & & 2 \\
\hline \multirow[t]{2}{*}{ N-E } & Mesotrophic & Nutrient deficiency & Tabellaria & & & & & & & 8 & 4 & 4 & \\
\hline & & & Carteria & & & & & & & & 3 & 2 & \\
\hline \multirow[t]{2}{*}{$\mathrm{U}$} & Epilimnion in summer & Low nutrients & Uroglena & & & & & & & & 8 & 19 & 7 \\
\hline & & Low nutrients & Monas & & & & & & & & 5 & 7 & 6 \\
\hline \multirow[t]{4}{*}{$\mathrm{F}$} & Clear epilimnia & Low nutrients & Kirchneriella & & & & & & & & 4 & 4 & 8 \\
\hline & & & Glenodinium & & & & & & & & 3 & 2 & 2 \\
\hline & & & Katablepharis & & & & & & & & 3 & 2 & 2 \\
\hline & Meso-oligotrophic & Low nutrients & Kephyrion & & & & & & & & 2 & 3 & 5 \\
\hline \multirow[t]{2}{*}{ B } & Mesotrophic & Light deficiency & Synedra & & & & & & 4 & & 2 & 4 & 3 \\
\hline & & & Erkenia & & & & & & & 4 & 4 & 7 & 4 \\
\hline $\mathrm{E}$ & Oligotrophic & Low nutrients (mixotrophy) & Mallomonas & & & & & & & 1 & 3 & 14 & 6 \\
\hline $\mathrm{E}$ & Oligotrophic & Low nutrients (mixotrophy) & Ochromonas & & & & & & & 6 & 1 & 1 & 1 \\
\hline $\mathrm{E}$ & Oligotrophic & Low nutrients (mixotrophy) & Dinobryon & & & & & & 14 & 6 & 6 & 5 & 4 \\
\hline A & Clear, base poor & Nutrient deficiency & Cyclotella & & & & & & 8 & 8 & & & \\
\hline A & Clear, base poor & Nutrient deficiency & Cyclotella/Stephanodiscus & & & & & & & & 2 & 7 & 11 \\
\hline
\end{tabular}

Only genera with a contribution of $\geq 1 \%$ are listed. Associations, habitat characteristics and tolerances are indicated according to Rosén (1981); Reynolds (1996) and Reynolds et al. (2002); fields are empty when no pertinent information is provided in those references. Terminology follows Reynolds et al. (2002). The contributions of genera that help to form axis I in at least three lakes are in boldface. In Lakes Zurich and Walen, the small centric diatoms were not reliably identified and Cyclotella was probably misclassified as Stephanodiscus hantzschii. To account for this limitation, we merged these diatoms into one category: Cyclotella/Stephanodiscus. 
Fig. 7) are characterised by genera that differ greatly in their traits. Genera associated with nutrient-rich habitats constitute part of the axis for both periods. In contrast, taxa characterised as mixotrophic and tolerant to low nutrient concentrations discriminate the years after 1988. Contributions of species which can be associated with a specific trophic status (Rosén, 1981; Reynolds, 1996; Reynolds et al., 2002) varied among the lakes. In Lakes Geneva, Constance and Walen these species contribute more than $50 \%$ of the interannual trend, while in both basins of Lake Zurich they contribute only $27 \%$ and $36 \%$, respectively. Some genera, however, were found in almost all the lakes. For example, Eudorina, often recorded in nutrient-rich habitats, characterised the first period in all the lakes, except in Lake Constance. The taxa Ochromonas and Mallomonas, which indicate oligotrophic conditions, contributed to the formation of axis I in Lakes Constance, Zurich and Walen. The genera Cyclotella and Dinobryon appeared during the second period in all the lakes. However, in the more eutrophic lakes (Lakes Geneva and Constance and Lower Lake Zurich), the taxa with the highest contributions to the second period were often lake-specific (16\% Gymnodinium in Lake Constance, $18 \%$ Planktothrix in Lower Lake Zurich, $18 \%$ Diatoma in Lake Geneva) and not necessarily indicators of low nutrient concentrations. Indeed, in Lake Constance, the genera Ceratium (4\%) and Diatoma $(6 \%)$, both indicative of eutrophic conditions, were most abundant during the 1990s. In Lower Lake Zurich, the same second period was dominated by Planktothrix rubescens (DC ex. Gom) Anagn. et Kom. (18\%), a species tolerant to low light and recognised as being the classic Central European indicator alga of eutrophication (Sommer, 1986). The same paradox was observed in Lake Geneva where the 1990s were mainly characterised by taxa tolerant to low light intensities, such as Diatoma (18\%), Mougeotia (5\%), P. rubescens (3\%), Pseudanabaena $(2 \%)$ and Tribonema (1\%).

\section{Discussion}

\section{Locally-driven coherence in phosphorus concentrations}

The studied lakes experienced a combination of environmental changes characterised by increasing water temperatures and strong variations in phosphorus concentrations. Because of local measures to reduce phosphorus inputs, concentrations have been decreasing in all the lakes, a trend that has been well documented (Gaedke, 1998; Anneville \& Pelletier, 2000; Gammeter \& Zimmermann, 2000). Lake Geneva and Lower Lake Zurich have changed from a eutrophic to a mesotrophic state, and Lake Constance is approaching the oligotrophic state. Lake Walen and Upper Lake Zurich, which have lower phosphorus concentrations, have changed from a mesotrophic to an oligotrophic state. In all the lakes, the reoligotrophication process is characterised by the earlier appearance of the seasonal P-depleted layer and the deepening of this depleted zone. Although the lakes differ in overall phosphorus concentration, the percentage reduction of TP concentration was similar, ranging from $67 \%$ to $87 \%$.

\section{Synchrony in phytoplankton changes}

Changes in phosphorus concentrations have a strong influence on phytoplankton, although it is often difficult to predict how identical changes in phosphorus concentrations will affect different lakes. However, although the lakes experienced comparable environmental changes caused by the same meteorological forcing and management programmes, total phytoplankton biomass fluctuated without any coherence among the lakes. Furthermore, apart from Lake Walen, where the decrease in phosphorus concentration was accompanied by a decrease in spring and summer phytoplankton biomass, and Lake Constance where a summer biomass decline was observed, quantitative changes in phytoplankton related to the phosphorus decreases did not occur. The lack of a response of phytoplankton biomass to the phosphorus decrease can be explained by compositional changes in phytoplankton communities, grazing by zooplankton, sedimentation and changes in self-shading. These factors might therefore distort the theoretically linear relationship between phosphorus and phytoplankton biomass (Jørgensen \& De Bernardi, 1998).

The results of our multivariate analysis underline the long-term changes in phytoplankton communities. Comparison of the main changes revealed temporal coherence whose strength depended on the season. Contrary to summer changes, spring variations were not coherent between all pairs of lakes. During spring, phytoplankton growth in the rather deep lakes considered in this study was strongly influenced by 
mixing depth and hence light limitation (Gaedke et al., 1998). Mixing depth depends strongly on highly unpredictable factors such as periods of high wind (Imboden, 1990) and mixing might occur during early spring, independent of water temperature, when stratification is still rather unstable. The frequency and intensity of wind-induced turbulences, which have a strong influence on phytoplankton composition (Reynolds, 1993), are expected to differ between the lakes. Furthermore, exposure to wind varied significantly among the lakes considered in this study. Hence, despite common increasing trends in winterspring water temperatures, climate change appeared not to be sufficient to generate synchronous long-term changes in phytoplankton community composition during spring. In contrast, there is a surprisingly strong temporal-coherence among lakes in summer, with the years falling within two distinct periods in all lakes: the first one gathering the 1970s and 1980s, the second one starting in 1988.

Phosphorus decrease as a determinant of a new summer phytoplankton composition

Changes in phytoplankton composition in the studied lakes were synchronous during summer. Despite differences in absolute phosphorus concentrations, oligotrophication appeared to be the main factor influencing those changes in community composition. TP concentration was most consistently related to the first principal component scores in our analysis, and the ecological traits of the species characterising these changes support this assertion. The changes in community structure, which reflect the dominant interannual change in phytoplankton community for each lake, were partly caused by the same taxa (Cyclotella and Dinobryon). That these common taxa are tolerant of low nutrient concentrations and often found in oligo-mesotrophic habitats (Rosén, 1981; Reynolds et al., 2002) is consistent with their increase in abundance in both Lake Constance (Gaedke, 1998; Kümmerlin, 1998) and Lake Geneva (Anneville et al., 2002a). Other taxa are known to occur in association with the ones mentioned above (see Table 3) or, like Uroglena, are tolerant and morphologically adapted to low nutrient concentrations (Reynolds, 1997).

However, in the more eutrophic lakes, the interannual trends are also triggered by specific taxa which are responsible for the observed resilience in total phytoplankton biomass. In Lake Geneva and Lower Lake Zurich, resilience was caused by different and larger taxa (e.g. Diatoma, Mougeotia, Tribonema, Planktothrix) that have been classified as R-adaptive-strategists and which are able to persist at low light availability (Reynolds, 1980,1984). This type of taxa is, therefore, favoured in habitats characterised by segregation of nutrients into deep waters (Reynolds, 1997); they constituted a characteristic summer assemblage in Lake Geneva in the 1990s (Anneville et al., 2002b). In Lake Constance, the relative importance of mixotrophic taxa has increased since the late 1980s, and the mass development of Ceratium might be explained by the capability of this dinoflagellate to migrate between the euphotic zone and deeper Penriched water layers under suitable hydrological conditions (Gaedke, 1998). This increase in mixotrophic taxa was not fast enough, however, to compensate for the pronounced decrease in other taxa, which led to the lower biomass values observed in recent summers (Gaedke, 1998).

\section{The potential influence of climate}

The major shift in community composition occurred in all lakes at the end of the 1980s, i.e. approximately at the same time although the absolute phosphorus concentrations differed several fold between lakes (Fig. 1). This suggests that additional factors might have contributed to this shift, which coincided with the first occurrence of a warm winter-spring period (Fig. 3) associated with the North Atlantic Oscillation (NAO) (Hurrell, 1995). The influence of climate is supported by the significant contribution of winter temperature and its interaction with TP concentration to the 'best' (according to Akaike's information criterion) mixed model explaining summer phytoplankton composition. The NAO is now recognised to have a strong influence on aquatic ecosystems (Gerten \& Adrian, 2001; Livingstone \& Dokulil, 2001; Straile, 2002; Beaugrand \& Reid, 2003; Straile et al., 2003b; George, Maberly \& Hewitt, 2004), including Lakes Constance and Geneva (Straile, 2000; Anneville et al., 2002b; Straile, Joehnk \& Rossknecht, 2003a). The influence of the NAO results in the widespread coherence of water temperature in peri-alpine lakes (Livingstone \& Dokulil, 2001), including Lakes Zurich and Walen (Anneville et al., 2004). Interestingly, a major shift related to the NAO seems to have occurred 
in the North Sea ecosystem also at the end of the 1980s (Reid et al., 1998; Beaugrand, 2004).

Several mechanisms might contribute to the link between winter temperatures, respectively the NAO, and phytoplankton community structure in our study lakes. The NAO is known to influence spring mixing intensity and nutrient availability (Straile et al., 2003a) and spring plankton population dynamics of herbivores (Straile, 2000; Anneville et al., 2002b). Hence, phytoplankton may be influenced indirectly through a change in nutrient availability as a result of altered mixing (bottom-up effect) and/or through changed herbivore grazing (top-down effect). Winter climate variability might influence summer nutrient concentrations, and hence, possible nutrient limitation of phytoplankton via several mechanisms. First, in addition to exerting top-down control on phytoplankton, Daphnia is also an important phosphorus drain for phytoplankton (Sommer et al., 2003). Hence, faster Daphnia population growth after mild winters is likely to contribute to increased nutrient limitation of phytoplankton. Second, higher winter temperatures and earlier stratification favour spring phytoplankton growth and enhance nutrient consumption in spring. This phytoplankton activity contributes to earlier and more severe phosphorus depletion in the epilimnion of Lake Geneva (Anneville et al., 2002b). Third, mild winters might result in incomplete winter mixing thus preventing complete nutrient replenishment of the trophogenic zone from the hypolimnion (Straile et al., 2003a; Salmaso, 2005). All these mechanisms can accelerate both the early occurrence of a depleted phosphorus layer and the deepening of the P-depleted zone in summer. This deepening will enhance the success of motile or low-light tolerant species in eutrophic-mesotrophic lakes (Anneville et al., 2002b). For example, the increased occurrence of Planktothrix in Lake Zurich in the second period is most probably because of a deepened phosphorus depleted layer in summer. However, reduced declines in population size during winter, as a result of reduced winter mixing, might also have contributed to the recent success of Planktothrix in this lake (Anneville et al., 2004).

\section{Conclusion}

The multivariate method used in the present study is an effective way to detect and characterise long-term changes in phytoplankton composition. Quantitative changes in phytoplankton composition are described by a quantitative variable allowing correlation and thus detection of temporal coherence. The results presented here reveal that regional trends in phytoplankton composition do occur and that coherence between lakes can be detected even if biomass fluctuates without synchrony. This observation suggests that phytoplankton community composition is a more sensitive measure of the effects of regional-scale processes than is biomass.

The study underlines the difficulty of separating the effects of climate change from nutrient effects resulting from management measures in the catchment. A decrease in phosphorus concentration appears to be the main determinant of changes in phytoplankton composition, but warmer winters may have an indirect influence on synchrony. Synchrony between geographically isolated phytoplankton communities appears to be linked to certain key variables controlling phytoplankton composition, and how coherently they change among lakes. In summer, when competition for nutrients is the main controlling mechanism, changes in nutrient concentrations are likely to induce synchrony in phytoplankton community changes. The observed changes have two components. The first is the expected response to a decrease in phosphorus concentration (via an increase in species having a high affinity for nutrients or are capable of mixotrophy), which can be generalised across lakes. The second is a 'lake-specific' response that may lead to resilience in total phytoplankton biomass in mesotrophic lakes. This 'lake-specific' response is of major importance for lake managers and underlines the importance of gaining a better understanding of local dynamics and processes leading to changes in phytoplankton composition.

\section{Acknowledgments}

The authors are grateful to everyone who contributed to the data sets and thank the INRA (Institut National pour la Recherche Agronomique) and the CIPEL (Commission Internationale pour la Protection des Eaux du Léman contre la pollution). The authors are grateful to Suzanne Zweisig for checking the English, to S. Souissi, J.C. Druart, Y. Reyjol and J. Lazzaroto for advice, U. Gaedke for providing the phytoplankton data, and the IGKB (Internationale 
Gewässerschutzkommission für den Bodensee) for providing phosphorus and temperature data from Lake Constance. We also thank the organisers of the LIMPACS workshop for a very stimulating week in Silkeborg. This work was supported by a Marie Curie Individual Fellowship of the European Commission and is a contribution to the IFB 'Institut Français de la Biodiversité' project 'Biodiversité et changement global' and to the European Commission's Environment and Sustainable Development Programme under contract EVK1-CT-2002-00121 (CLIME).

\section{References}

AFNOR (1982) Essais des eaux: Nome française, dosage des orthophosphates, des polyphosphates et du phosphore total (méthode spectrométrique). NFT 90-023, AFNOR, $10 \mathrm{pp}$.

Anneville O. \& Pelletier J.-P. (2000) Recovery of Lake Geneva from eutrophication: quantitative response of phytoplankton. Archiv für Hydrobiologie, 148, 607-624.

Anneville O., Ginot V. \& Angeli N. (2002a) Restoration of Lake Geneva: expected versus observed responses of phytoplankton to decreases in phosphorus. Lakes and Reservoirs: Research and Management, 7, 67-80.

Anneville O., Souissi S., Gammeter S. \& Straile D. (2004) Seasonal and inter-annual scales of variability in phytoplankton assemblages: comparison of phytoplankton dynamics in three peri-alpine lakes over a period of 28 years. Freshwater Biology, 49, 98-115.

Anneville O., Souissi S., Ibanez F., Ginot V. \& Angeli N. (2002b) Temporal mapping of phytoplankton assemblages in Lake Geneva: annual and interannual changes in their patterns of succession. Limnology and Oceanography, 47, 1355-1366.

Baines S.B., Webster K.E., Kratz T.K., Carpenter S.R. \& Magnuson J.J. (2000) Synchronous behavior of temperature, calcium, and chlorophyll in lakes of northern Wisconsin. Ecology, 81, 815-825.

Beaugrand G. (2004) The North Sea regime shift: evidence, causes, mechanisms and consequences. Progress in Oceanography, 60, 245-262.

Beaugrand G. \& Reid P.C. (2003) Long-term changes in phytoplankton, zooplankton and salmon related to climate. Global Change Biology, 9, 801-817.

DEV (1996) Deutsche Einheitsverfahren zur Wasser-, Abwasser und Schlamm-Untersuchung I-V, 1-36, VCH Verlagsgesellschaft mbH, Weinheim, 1996.

Dolédec S. \& Chessel D. (1989) Rythmes saisonniers et composantes stationnelles en milieu aquatique II Prise en compte et élimination d'effets dans un tableau faunistique. Acta CEcologica, CEcologia Generalis, 10, 207232.

Gaedke U. (1998) Functional and taxonomical properties of the phytoplankton community of large and deep Lake Constance: interannual variability and response to re-oligotrophication (1979-93). Archiv für Hydrobiologie - Advances in Limnology, 53, 119-141.

Gaedke U., Hochstädter S. \& Straile D. (2002) Interplay between energy limitation and nutritional deficiency: empirical data and food web models. Ecological Monographs, 72, 251-270.

Gaedke U., Ollinger D., Bäuerle E. \& Straile D. (1998) The impact of the interannual variability in hydrodynamic conditions on the plankton development in Lake Constance in spring and summer. Archiv für Hydrobiologie - Advances in Limnology, 53, 565-585.

Gammeter S. \& Zimmermann U. (2000) Changes in phytoplankton productivity and composition during reoligotrophication in two Swiss lakes. Verhandlungen der Internationalen Vereinigung für Limnologie, 27, 21902193.

George D.G., Maberly S.C. \& Hewitt D.P. (2004) The influence of the North Atlantic Oscillation on the physical, chemical and biological characteristics of four lakes in the English Lake District. Freshwater Biology, 49, 760-774.

Gerten D. \& Adrian R. (2001) Differences in the persistency of the North Atlantic Oscillation signal among lakes. Limnology and Oceanography, 46, 448-455.

Hurrell J.W. (1995) Decadal trends in the North Atlantic Oscillation: regional temperatures and precipitations. Science, 269, 676-679.

Imboden D.M. (1990) Mixing and transport in lakes: mechanisms and ecological relevance. In: Large Lakes, Ecological Structure and Function (Eds M.M. Tilzer and C. Serruya), pp. 47-80. Springer Verlag, Berlin.

Jørgensen S.E. \& De Bernardi R. (1998) The use of structural dynamic models to explain successes and failures of biomanipulation. Hydrobiologia, 379, 147158.

Kratz T.K., Soranno P.A., Baines S.B., Benson B.J., Magnuson J.J., Frost T.M. \& Lathrop R.C. (1998) Interannual synchronous dynamics in north temperate lakes in Wisconsin, USA. In: Management of Lakes and Reservoirs during Global Change (Eds D.G. George and D.W. Sutcliffe), pp. 273-287. Kluwer Academic Publishers, Netherlands.

Kümmerlin R.E. (1998) Taxonomical response of the phytoplankton community of Upper Lake Constance (Bodensee-Obersee) to eutrophication and re-oligotrophication. Archiv für Hydrobiologie - Advances in Limnology, 53, 109-117. 
Littell R.C., Miliken G.A., Stroup W.W. \& Wolfinger R.D. (1996) SAS System for Mixed Models. SAS Institute, Inc, Cary, NC.

Livingstone D.M. \& Dokulil M. (2001) Eighty years of spatially coherent Austrian lake surface temperatures and their relationship to regional air temperature and the North Atlantic Oscillation. Limnology and Oceanography, 46, 1220-1227.

Magnuson J.J. \& Kratz T.K. (2000) Lakes in the landscape: approaches to regional limnology. Verhandlungen der Internationalen Vereinigung für Limnologie, 27, 74-87.

Pace M.L. (2001) Prediction and the aquatic sciences. Canadian Journal of Fisheries and Aquatic Sciences, 58, 6372.

Reavie E. \& Smol J. (2001) Diatom-environmental relationships in 64 alkaline southeastern Ontario (Canada) lakes: a diatom-based model for water quality reconstructions. Journal of Paleolimnology, 25, 25-42.

Reid P.C., Edwards M., Hunt H.G. \& Warner A.J. (1998) Phytoplankton change in the North Atlantic. Nature, 391, 546.

Reynolds C.S. (1980) Phytoplankton assemblages and their periodicity in stratifying lake systems. Holarctic Ecology, 3, 141-159.

Reynolds C.S. (1984) The Ecology of Freshwater Phytoplankton. Cambridge University Press, New York, 384 pp.

Reynolds C.S. (1993) Scales of disturbance and their role in plankton ecology. Hydrobiologia, 249, 157-171.

Reynolds C.S. (1996) The plant life of the pelagic. Verhandlungen der Internationalen Vereinigung für Limnologie, 26, 97-113.

Reynolds C.S. (1997) Vegetation Processes in the Pelagic: a Model for Ecosystem Theory. Ecology Institute, Oldendorf/Luhe, Germany, 371 pp.

Reynolds C.S., Huszar V., Kruk C., Naselli-Flores L. \& Melo S. (2002) Towards a functional classification of the freshwater phytoplankton. Journal of Plankton Research, 24, 417-428.

Rosén G. (1981) Phytoplankton indicators and their relations to certain chemical and physical factors. Limnologica, 13, 263-290.

Rusak J.A., Yan N.D., Somers K.M. \& McQueen D.J. (1999) The temporal coherence of zooplankton popula- tion abundances in neighboring north-temperate lakes. American Naturalist, 153, 46-58.

Salmaso N. (2005) Effects of climatic fluctuations and vertical mixing on the interannual trophic variability of Lake Garda, Italy. Limnology and Oceanography, 50, 553565.

SAS (1999) SAS/STAT User's Guide, Version 8. SAS Institute, Cary, NC.

Sommer U. (1986) The periodicity of phytoplankton in Lake Constance (Bodensee) in comparison to other deep lakes of central Europe. Hydrobiologia, 138, 1-7.

Sommer F., Santer B., Jamieson C., Hansen T. \& Sommer U. (2003) Daphnia population growth but not moulting is a substantial phosphorus drain for phytoplankton. Freshwater Biology, 48, 67-74.

Straile D. (2000) Meteorological forcing of plankton dynamics in a large and deep continental European lake. Oecologia, 122, 44-50.

Straile D. (2002) North Atlantic Oscillation synchronizes food-web interactions in central European lakes. Proceedings of the Royal Society of London Series B, 269, 391395.

Straile D., Joehnk K. \& Rossknecht H. (2003a) Complex effects of winter warming on the physico-chemical characteristics of a deep lake. Limnology and Oceanography, 48, 1432-1438.

Straile D., Livingstone D.M., Weyhenmeyer G.A. \& George D.G. (2003b) The response of freshwater ecosystems to climate variability associated with the North Atlantic Oscillation. In: The North Atlantic Oscillation: Climatic Significance and Environmental Impact. Geophysical Monograph Series (eds J.W. Hurrell, Y. Kushnir, G. Ottersen, \& M. Visbeck ), pp. 263-279. 134, American Geophysical Union, Washington, DC.

Thioulouse J., Chessel D., Dolédec S. \& Olivier J.M. (1997) ADE-4: a multivariate analysis and graphical display software. Statistics and Computing, 7, 75-83.

Utermöhl H. (1958) Zur Vervollkommnung der quantitativen Phytoplankton-Methodik. Mitteilungen der Internationalen Vereinigung für Limnologie, 9, 1-38. 